\title{
Cell division in the synovial lining in experimental allergic arthritis: proliferation of cells during the development of chronic arthritis
}

\author{
B. HENDERSON, L. E. GLYNN, AND J. CHA YEN \\ From the Division of Cellular Biology, Kennedy Institute of Rheumatology, Bute Gardens, London W6 7DW
}

SUMMARY The synovial tissue in experimentally induced immune arthritis induced in the rabbit has been used as a model of rheumatoid arthritis to determine which cells may contribute to the growth of this tissue. Tissue from the challenged and from the unchallenged knee joints was taken, after the intra-articular injection of a small amount of tritiated thymidine, from rabbits up to 3 months after the arthritis was induced. DNA synthesis, as a measure of cell proliferative activity, was assessed firstly by measuring the labelling index in autoradiographs of sections of such tissue, and secondly by the DNA synthetic index obtained by Feulgen cytophotometry. These measurements were made separately on synoviocytes, on the structural cells of the stroma, on the cells lining the small blood vessels, and on the infiltrating inflammatory cells. The DNA synthetic activity of the synoviocytes, and of the stromal noninflammatory cells, was maximal between 3 and 7 days after challenge. The activity in the synoviocytes, in particular, remained raised for up to 84 days after the challenge. Thus these cells appear to be capable of contributing to the hyperplasia, but the contribution of other cells, deeper in the stroma, cannot be excluded.

The intra-articular injection of antigen (normally ovalbumin) into rabbits, sensitised by immunisation with antigen in Freund's complete adjuvant (FCA), results in a chronic inflammation in the synovium which closely resembles that found in rheumatoid arthritis. ${ }^{1-4}$ Among the changes produced in the synovium, as a result of the inflammation is the hyperplasia of many of the cell populations found in the normal tissue: synoviocytes, fibroblasts, mesenchymal cells, and cells of the synovial vasculature. In addition the synovium is infiltrated with chronic inflammatory cells. In a previous paper it was reported that during the acute inflammatory phase, between 1 and 5 days following challenge, a marked increase occurred in the rate of cell division by the synoviocytes. ${ }^{5}$ In this paper we detail the rates of cellular proliferation in the synoviocytes, fibroblasts, and mesenchymal cells, cells of the blood vessels, and chronic inflammatory cells in the synovium during the development of chronic arthritis in the knee joint of the rabbit.

Accepted for publication 29 April 1981.

Correspondence to Dr J. Chayen, Division of Cellular Biology, Kennedy Institute of Rheumatology, Bute Gardens, London W6 7DW.

\section{Materials and methods}

For this study 44 rabbits (Old English strain, obtained from Cheshire Rabbit Farms, Tarporley, Cheshire; weight $2-3 \mathrm{~kg}$ ) of either sex were used. Animals were immunised with ovalbumin (KochLight: $5 x$ crystallised) in Freund's complete adjuvant as in the procedure of Consden et al. ${ }^{2}$ except that 0.5 $\mathrm{ml}$ instead of $1.0 \mathrm{ml}$ of the emulsion was used for sensitisation. When skin tests showed that the animals had developed a delayed-type hypersensitivity reaction to ovalbumin, the right knee was injected with $1 \mathrm{ml}$ of a sterile solution of ovalbumin (10 $\mathrm{mg} / \mathrm{ml}$ ) in saline. As a control the left knee was injected with the same volume of sterile saline. Animals were killed between 1 day and 3 months ( 84 days) after intra-articular challenge; 1-2 hours before killing, $1 \mathrm{ml}$ of tritiated thymidine $\left({ }^{3} \mathrm{HTdR}\right.$; TRA 120, Amersham: $10 \mu \mathrm{Ci} / \mathrm{ml}$ ) in sterile saline was injected intra-articularly into each knee.

Preparation of tissues. The synovium was dissected from both knee joints and chopped into blocks $1-4 \mathrm{~mm}^{3}$

Histology. Paraffin sections (4 $\mu \mathrm{m}$ thick, prepared as described below) were stained with haematoxylin and eosin or with safranin 0 counterstained with light 
green. Cryostat sections ( $10 \mu \mathrm{m}$ thick) were stained with haematoxylin and eosin or with toluidine blue.

Autoradiography. Tissue blocks (normally 6-12 from each joint) were fixed first in acetic acid:ethanol $(1: 3 \mathrm{v} / \mathrm{v})$ for $1 \mathrm{~h}$ (to remove unincorporated ${ }^{3} \mathrm{HTdR}$ ) and then in buffered formol saline for $24 \mathrm{~h}$. The blocks of tissue were then transferred to $70 \%$ ethanol prior to embedding in paraffin. Sections were cut at 4 $\mu \mathrm{m}$, mounted on subbed slides, dewaxed, and coated with Ilford K5 emulsion. The slides were exposed for 2 weeks, developed, and then stained with haematoxylin and eosin. With some animals cryostat sections $(8 \mu \mathrm{m}$ thick, prepared as described by Chayen et al. $^{6}$ ) were used for autoradiography. These were fixed for $10 \mathrm{~min}$ in 1:3 acetic ethanol, dried, and coated with emulsion as was done for paraffin sections. Labelling indices (LI) were obtained by counting the number of labelled nuclei in any one population of cells as a proportion of all the nuclei in that cell population in the region examined. Counting of cells was facilitated by the use of 'masks' of various sizes, which fitted into the eyepiece and encompassed a defined average number of cells. Because of the variation in the proportion of labelled cells in different areas of the synovium, labelling indices were measured normally in 3-6 blocks of tissue from the joints of each animal in order to obtain an average value representative of the cellular proliferation in the synovium as a whole. Tissue blocks were chosen for measurement at random (i.e., from the 6-12 blocks processed for autoradiography) and not simply because of the presence of labelled cells, thus ensuring that a representative sample of the labelling in the tissue was obtained. Labelling indices were measured in the synovial lining cell layer, in the small and large blood vessels of the stroma, in inflammatory cells, and in the connective tissue cells lying deeper in the stroma of the synovium (i.e., more than 20 cells in depth from the synovial lining cell layer).

Feulgen microdensitometry. The Feulgen reaction was performed on $10 \mu \mathrm{m}$ thick cryostat sections of the synovium. The methods used to prepare tissue for

\section{SYNOVIOCYTES}

STROMAL CELLS
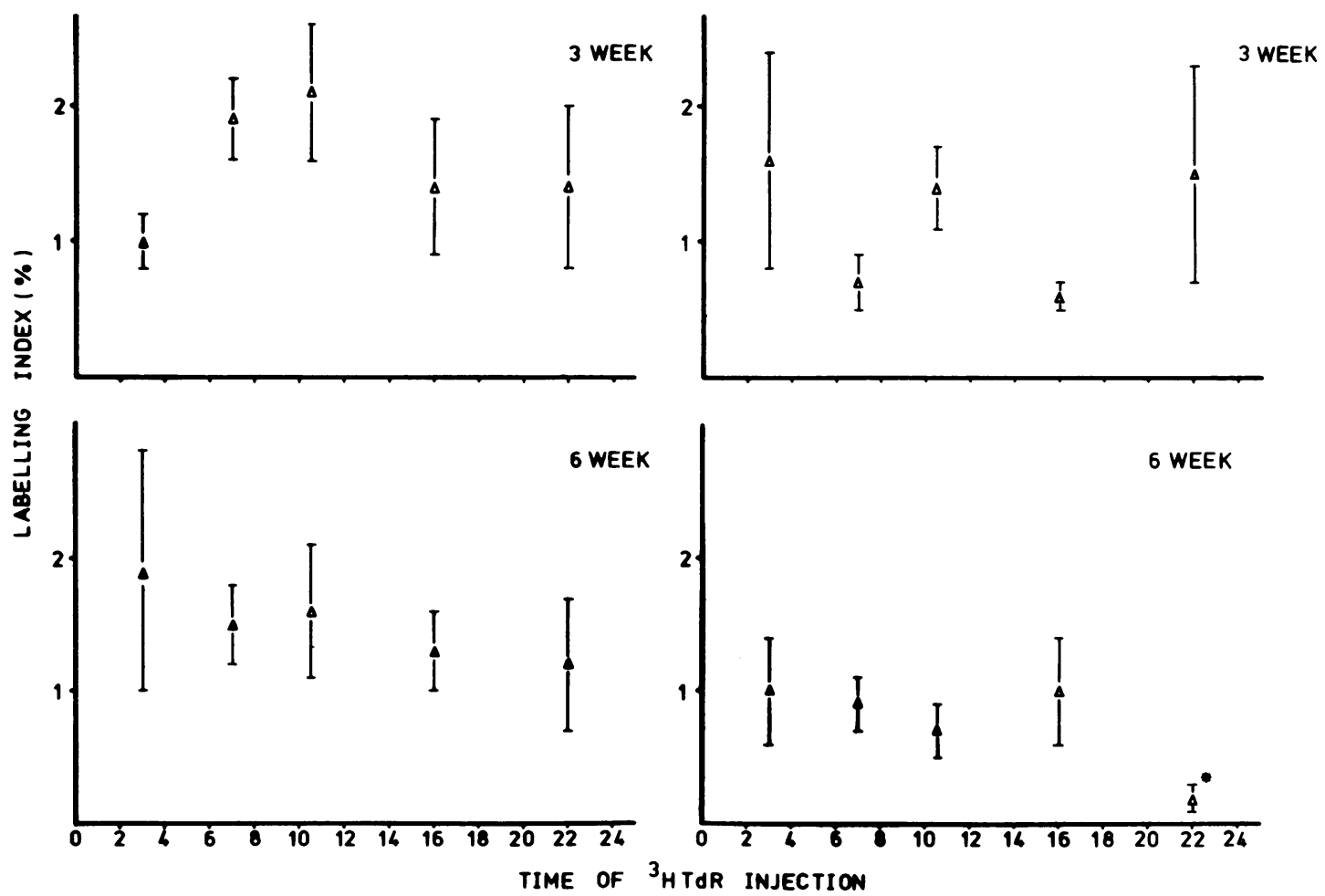

Fig. 1 Labelling indices in the synoviocytes and stromal cells of animals killed at various times during the day. Results are presented as mean $\pm S E M$ of the labelling indices in various blocks of synovial lining from the same animal ( ${ }^{*}$ not significantly different). 


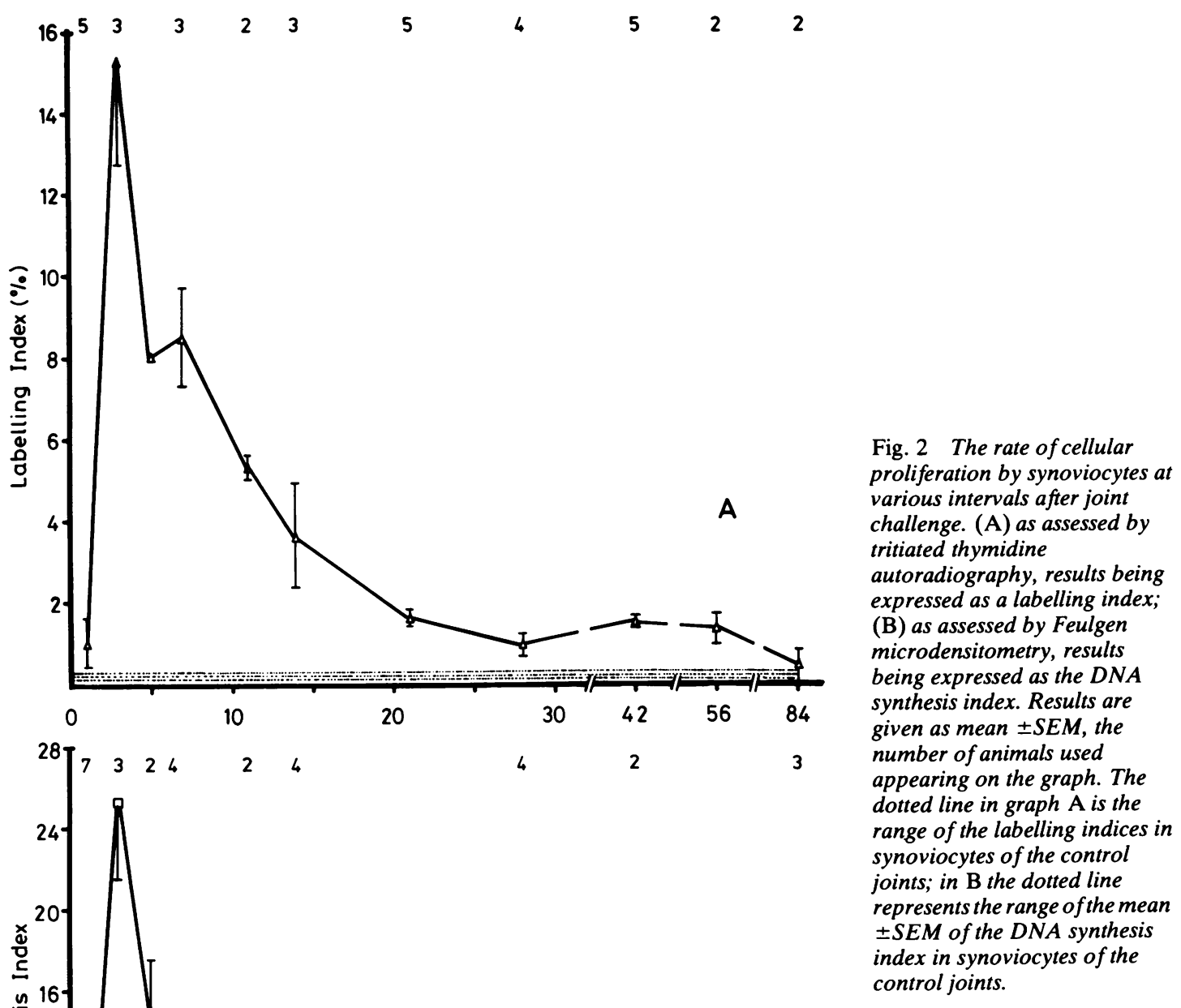

B

cryotomy, and for reacting and measuring sections, have been fully described by Henderson $e t$ al. ${ }^{5}$

\section{Results}

Labelling indices in animals killed at various times during the day. To test whether mitotic activity varied

with the time of day, labelled thymidine was injected into the joints of 5 animals 3 weeks after challenge, and 5 animals 6 weeks after challenge, at the following times: $0300,0700,1100,1600$, and $2200 \mathrm{~h}$. The animals were killed one hour later. The labelling indices in the synoviocyte layer and in the cells of the synovial stroma were measured in 4-6 blocks of the 


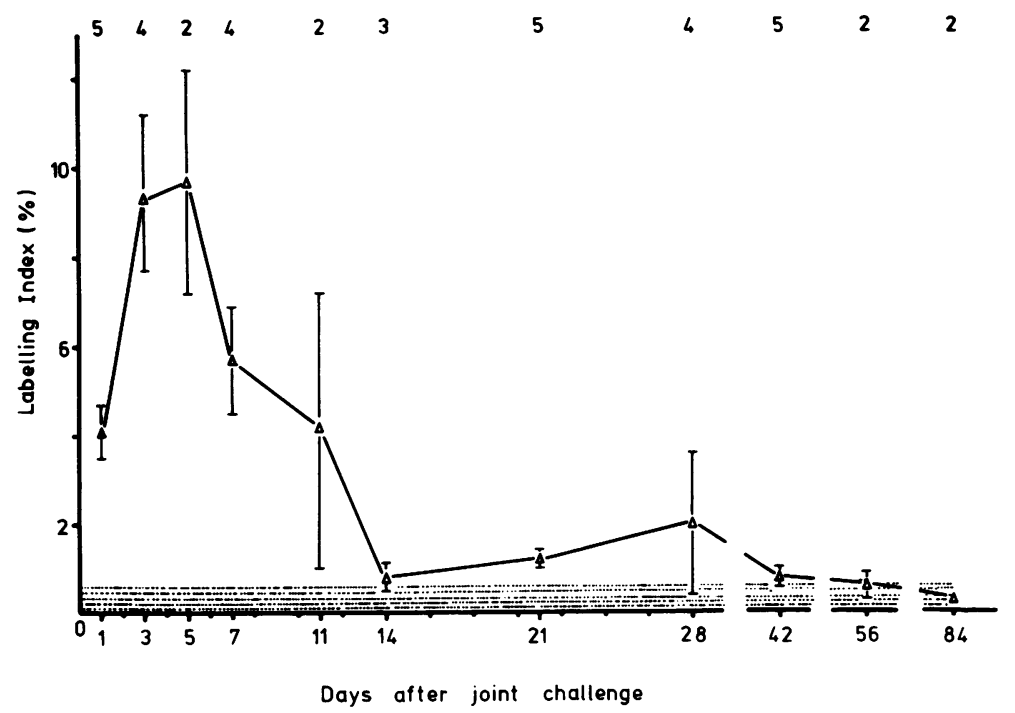

Fig. 3 The labelling indices for the stromal cells of the inflamed synovial linings of animals killed at various intervals after joint challenge. Results are expressed as the mean $\pm S E M$, the number of animals used at each interval appearing on the graph. The dotted line gives the range of the labelling indices found in stromal cells in control joints.

synovium from the inflamed joint of each animal. No significant differences were noted in the labelling indices of these animals killed at various times during the day (Fig. 1).

Proliferation of synoviocytes. The rate of cellular proliferation in the synoviocyte layer of the joints of untreated rabbits or of the control (saline-injected) joints of immunised rabbits was low; the range of ${ }^{3} \mathrm{HTdR}$ labelling indices was $0-0 \cdot 3 \%$. The labelling index in the synoviocytes of the inflamed joints was only slightly raised at $24 \mathrm{~h}$ after challenge, but by 3 days had reached $15 \cdot 3 \pm 2 \cdot 6 \%$ (mean \pm SEM; 3 animals). Between 3 and 14 days after challenge the labelling index fell rapidly from this peak value until at day 14 the average labelling index was $3 \cdot 6 \pm 1 \cdot 6 \%$ (3 animals). After this time the rate of decline of the labelling index diminished, and only after 84 days following joint challenge did the labelling index in the inflamed joints overlap with that in the control joints (Fig. 2A). In the animals killed at 84 days there were still signs of chronic inflammation in the synovium, including the presence of lymphoid follicles.

A somewhat similar pattern of proliferation was found when DNA synthesis was measured, in separate blocks of tissue from the same animals, by Feulgen microdensitometry (Fig. 2B).

Proliferation of connective tissue cells of the synovial stroma. As with the synoviocytes, there was little incorporation of tritiated thymidine into the connective tissue cells of the stroma (subintima) of normal or control synovial tissue. However $24 \mathrm{~h}$ after the injection of ovalbumin into the knee joints the mean labelling index in these cells was significantly raised $(4 \cdot 1 \pm 0 \cdot 6 \%$ : mean $\pm \mathrm{SEM})$. Maximum labelling was found between day 3 and day $5(9 \cdot 3 \pm 1 \cdot 9 \%$ at day 3 and $9 \cdot 7 \pm 2 \cdot 5 \%$ at day 5 : mean \pm SEM). The labelling indices declined rapidly after day 5 until at day 14 they overlapped with the range of labelling indices found in the control joints $(0-0.5 \%)$. Between day 14 and day 42 there was a second, but smaller, peak of ${ }^{3} \mathrm{HTdR}$ labelling. However, at 56 days and also at 84 days after challenge the labelling indices in inflamed and control joints were similar (Fig. 3).

Proliferation of cells of the blood vessels. No incorporation of tritiated thymidine was found in the blood vessels of the control joints of the 38 animals injected intra-articularly with this label. In challenged joints label was incorporated by both endothelial and smooth muscle cells of both veins and arteries (Fig. 4).

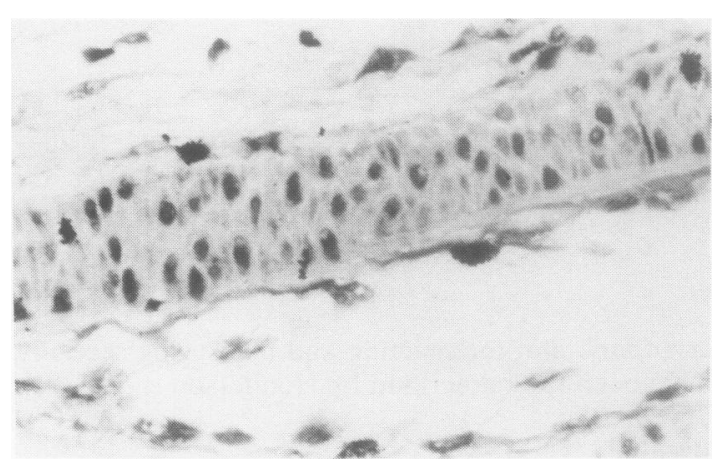

Fig. 4 Section of inflamed synovial lining from an animal killed 7 days after joint challenge showing label in the smooth muscle cells of a blood vessel. ( $H$ and $E, \times 283$ ). 


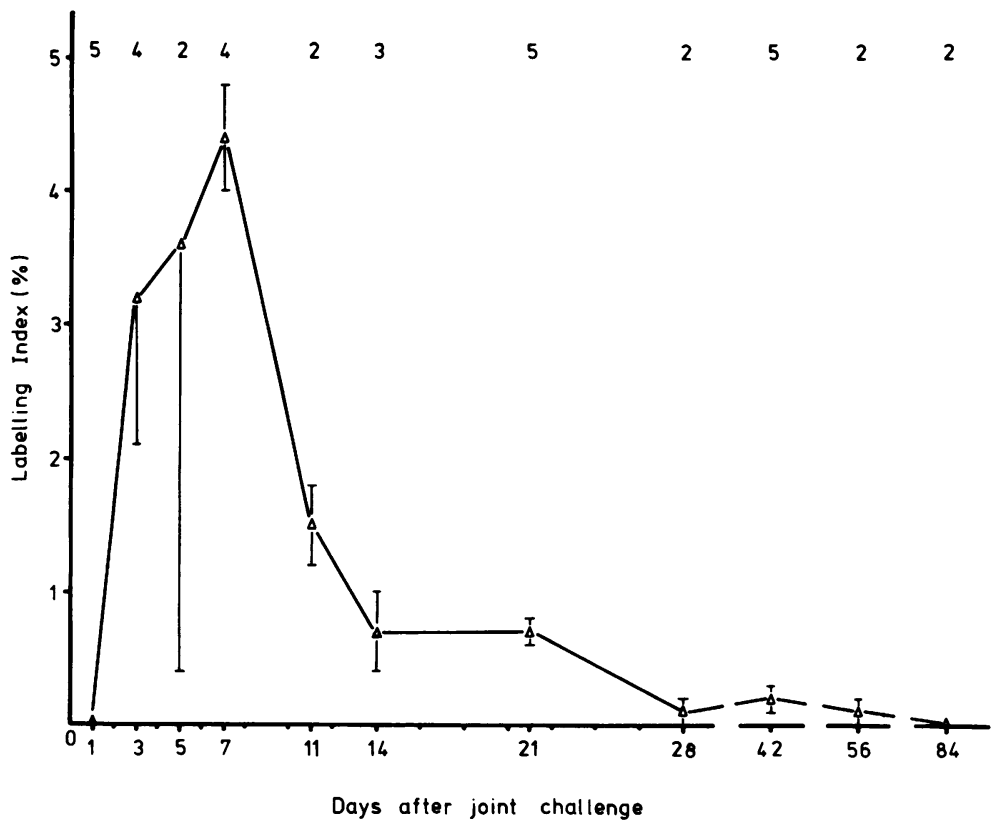

Fig. 5 The labelling indices in the blood vessels of the inflamed synovial linings of animals killed at various times after joint challenge. Results are expressed as mean $\pm S E M$, the number of animals used at each point in time being given on the graph.

No label was found in the blood vessels of any of the 5 rabbits killed $24 \mathrm{~h}$ after challenge. However, by 3 days after challenge the average labelling index in the vessels was $3 \cdot 2 \pm 1 \cdot 1 \%$ (mean \pm SEM. Maximum labelling was found 7 days after challenge ( $4 \cdot 4$ $\pm 0.4 \%$; mean \pm SEM: 4 animals); thereafter incorporation of ${ }^{3} \mathrm{HTdR}$ declined in much the same manner as with the synoviocytes (Fig. 5).
Incorporation of ${ }^{3} H T d R$ by inflammatory cells. Cells normally found at sites of chronic inflammation (macrophages, lymphocytes, and plasma cells) were found in the inflamed synovium at 3 days after challenge to the joint. Label was found in the nuclei of these inflammatory cells (in lymphocytes and in macrophages) at all sampling times from 3 days after challenge, except for the two animals killed after 84
Fig. 6 The labelling indices of the chronic inflammatory cells of the inflamed synovial linings of rabbits killed at various times after challenge. Results are expressed as mean $\pm S E M$. The number of animals used at each point in time is shown on the graph.

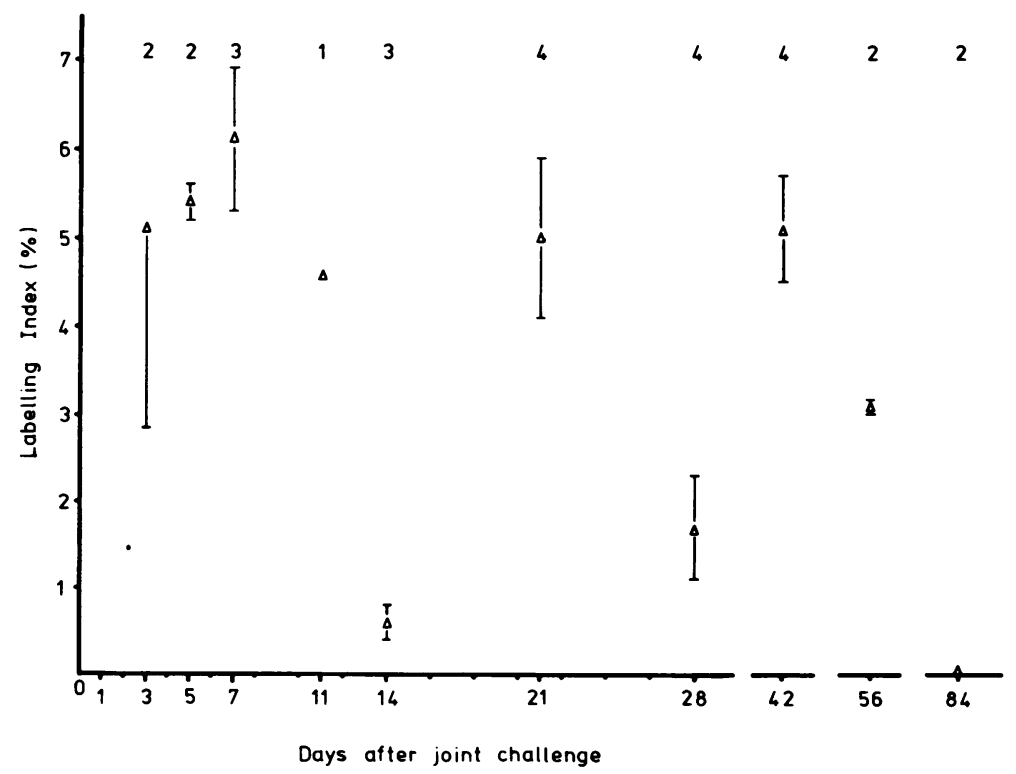


Table 1 Variation in labelling indices between different areas of synovial lining from the same joint

\begin{tabular}{|c|c|c|c|c|c|}
\hline \multirow{2}{*}{$\begin{array}{l}\text { Duration } \\
\text { inflamma- } \\
\text { tion, days }\end{array}$} & \multicolumn{3}{|l|}{ Synoviocytes } & \multicolumn{2}{|l|}{ Stromal cells } \\
\hline & $\begin{array}{l}\text { Labelling } \\
\text { index, } \\
\text { mean } \pm S D\end{array}$ & $\begin{array}{l}\text { Coefficient } \\
\text { of variation } \\
(\%)\end{array}$ & $\begin{array}{l}\text { Duration } \\
\text { of inflam- } \\
\text { mation }\end{array}$ & $\begin{array}{l}\text { Labelling } \\
\text { index, } \\
\text { mean } \pm S D\end{array}$ & $\begin{array}{l}\text { Coefficient } \\
\text { of variation } \\
(\%)\end{array}$ \\
\hline 3 & \multicolumn{2}{|c|}{$20 \cdot 5 \pm 8 \cdot 6(3)$} & 3 & \multicolumn{2}{|c|}{$14 \cdot 3 \pm 11 \cdot 0(3) 77$} \\
\hline 7 & $6 \cdot 8 \pm 4 \cdot 5(3)$ & 66 & 7 & \multicolumn{2}{|c|}{$6.1 \pm 3.6(3) 59$} \\
\hline 11 & \multicolumn{2}{|c|}{$5 \cdot 5 \pm 2 \cdot 9(4) 53$} & 7 & \multicolumn{2}{|c|}{$8 \cdot 7 \pm 6.8(4) 78$} \\
\hline 14 & \multicolumn{2}{|c|}{$3 \cdot 8 \pm 4 \cdot 8(3) 126$} & 7 & \multicolumn{2}{|c|}{$4 \cdot 0 \pm 4 \cdot 1(3) 103$} \\
\hline 21 & \multicolumn{2}{|c|}{$1.9 \pm 0.8(6) \quad 42$} & 14 & \multicolumn{2}{|c|}{$0.3 \pm 0.3(4) 100$} \\
\hline 21 & \multicolumn{2}{|c|}{$2 \cdot 1 \pm 1 \cdot 0(5) \quad 48$} & 21 & \multicolumn{2}{|c|}{$0.7 \pm 0.5(6) 71$} \\
\hline 21 & $1.4 \pm 0.9(4)$ & 64 & 21 & \multicolumn{2}{|c|}{$1.4 \pm 0.8(6) 57$} \\
\hline 21 & $1 \cdot 4 \pm 1 \cdot 3(4)$ & 93 & 21 & \multicolumn{2}{|c|}{$0.6 \pm 0.3(5) 50$} \\
\hline 21 & $1 \cdot 0 \pm 0.5(6)$ & 50 & 21 & \multicolumn{2}{|c|}{$1 \cdot 5 \pm 1.6(4) 107$} \\
\hline 42 & $1 \cdot 5 \pm 0 \cdot 5(3)$ & 33 & 21 & \multicolumn{2}{|c|}{$1 \cdot 7 \pm 1 \cdot 9(6) 112$} \\
\hline 42 & $1 \cdot 6 \pm 1 \cdot 0(4)$ & 63 & 42 & \multicolumn{2}{|c|}{$0.9 \pm 0.4(4) 44$} \\
\hline 42 & \multicolumn{2}{|c|}{$1 \cdot 3 \pm 0 \cdot 5(3) \quad 38$} & 42 & \multicolumn{2}{|c|}{$0.7 \pm 0.3(4) 43$} \\
\hline \multirow[t]{4}{*}{42} & \multirow{2}{*}{\multicolumn{2}{|c|}{$1.9 \pm 0.9(4) 100$}} & 42 & \multicolumn{2}{|c|}{$1.0 \pm 0.6(3) 60$} \\
\hline & & & 42 & $0.2 \pm 0.2$ & 3) 100 \\
\hline & \multirow{2}{*}{\multicolumn{2}{|c|}{ Range $33-126 \%$}} & 42 & $1.0 \pm 0.9$ & 5) 90 \\
\hline & & & & \multicolumn{2}{|c|}{$\begin{array}{l}1.0 \pm 0.9(3) \\
\text { Range 43-112\% }\end{array}$} \\
\hline
\end{tabular}

$($ ) = Number of blocks of tissue measured.

days. The labelling indices in the inflammatory cells varied widely, from no label at 84 days to $3-6 \%$ at days $3,5,7,11,21,42$, and 56 after challenge. The average labelling indices in animals killed 14 and 28 days after challenge were lower: $0.6 \%$ and $1.7 \%$ respectively. No pattern could be discerned in this variation in labelling indices (Fig. 6).

Variation in labelling index between different areas of the synovial lining. In these studies between 6 and 12 tissue blocks of synovium were examined. Measurement of the labelling index, both in the synoviocytes and in the connective tissue cells of the synovial stroma of the inflamed joints, revealed that in each rabbit examined there was a marked variation in this index between different areas of the synovial lining (Table 1). Such variation was also found with synoviocytes when DNA synthesis was measured by Feulgen microdensitometry. These differences in the rates of cellular proliferation may have been related to the region of the joint from which the tissue block was taken. Removal of synovium from 5 separate regions of the joint (fat

Table 2 Variation in labelling indices between known areas of the synovial lining

\begin{tabular}{lll}
\hline $\begin{array}{l}\text { Area of synovial } \\
\text { lining }\end{array}$ & \multicolumn{2}{l}{ Labelling index, mean $\pm S D$} \\
\cline { 2 - 3 } & Synoviocytes & Stromal cells \\
\hline Fat pad & $0 \cdot 7 \pm 0 \cdot 2(4)$ & $1 \cdot 3 \pm 0 \cdot 8(5)$ \\
Meniscus & $1 \cdot 5 \pm 0 \cdot 5(5)$ & $0 \cdot 4 \pm 0 \cdot 3(5)$ \\
Patella & $1 \cdot 9 \pm 1 \cdot 1(4)$ & $2 \cdot 1 \pm 2 \cdot 0(5)$ \\
Posterior & $1 \cdot 4 \pm 0 \cdot 7(4)$ & $0 \cdot 6 \pm 0 \cdot 3(4)$ \\
Margin & $1 \cdot 1 \pm 0 \cdot 2(4)$ & $0.6 \pm 0.3(4)$ \\
\hline
\end{tabular}

$(\mathrm{)}=$ Number of animals studied. pad, meniscus, patella, margins of the articular cartilage, and posterior pouch of joint) from the inflamed joints of the rabbits killed 3 or 6 weeks after challenge revealed that, although the synovium attached to the patella had the greatest labelling index both in synoviocytes and stromal cells, the spread of the results made differences between these separate regions of the lining nonsignificant (Table 2).

\section{Discussion}

Measurements of labelling indices and of DNA synthesis can be confused by sampling error, either because the synthesis of DNA occurs only at particular times of the day, as in the study by Coulton ${ }^{7}$ on wound healing in skin, or because such synthesis is restricted to certain regions of the tissue. In the present study it was shown that there was no appreciable circadian rhythm in the labelling index in the inflamed joints of rabbits 3 or 6 weeks after challenge (Fig. 1). The possibility that different regions had different DNA synthetic activities posed greater problems. Because the synovial lining from the rabbits used for the experiments described in this paper was also being used for studies of the metabolic activity of the lining, the whole joint could not be sectioned for autoradiography. The experimental protocol used, therefore, was to take 6-12 tissue blocks of synovium at random for autoradiography and an equivalent number for metabolic studies. Measurement of the labelling indices in the inflamed synovium revealed that different blocks of tissue displayed marked differences in the proportion of stromal cells or synoviocytes labelled. Thus all the labelling indices reported in this communication are the means of measurements in a number of regions (tissue blocks) of the synovium. The coefficients of variation for the labelling indices in synoviocytes and stromal cells are given in Table 1 , the range of variation being between $33 \%$ and $126 \%$. There was no clear relationship between the labelling index in the synovial tissue and the region of the joint from which the synovial tissue block was removed (Table 2). It would therefore appear from these findings that the inflamed synovium is not an autonomous tissue, but that different regions within the lining can undergo widely different amounts of cell proliferation, perhaps as a result of local factors such as blood flow.

The object of the present study was to define the source of proliferating cells that could contribute to the synovial hyperplasia that is characteristic of the chronic arthritis both in the human disease and in this model of the disease. The results showed that the synovial lining cells underwent DNA synthesis for cell proliferation not only in the first few days of acute 
inflammation but also for an extended period, so that even 56 days after challenge there was an appreciably raised labelling index (Fig. 2A). However, DNA synthetic activity was not restricted to the synovial lining cells. Over the first 11 days (Fig. 3) almost comparable activity was found in cells, deeper in the stroma, that resembled fibroblasts and other mesenchymal cells but were not infiltrating cells. The DNA synthetic activity of such cells fluctuated with time after challenge, remaining raised above control values for up to 28 days after challenge. Infiltrating cells also incorporated tritiated thymidine; more surprisingly foci of such activity were also found in endothelial and smooth muscle cells of established blood vessels. Thus it seems that the synoviocytes are capable of contributing to the synovial lining cell hyperplasia. Whether the proliferative activity of other connective tissue cells within the synovial tissue gives rise to cells that can differentiate to contribute to the turnover or hyperplasia of the synoviocyte layer remains to be elucidated.
We are grateful to the Medical Research Council for specific support for this work and to the Arthritis and Rheumatism Council for Research for general support. We also acknowledge the technical help of Miss I. R. Ellis.

\section{References}

${ }^{1}$ Dumonde D C, Glynn L E. The production of arthritis in rabbits by an immunological reaction to fibrin. BrJ Exp Pathol 1962; 43: 373-83.

2 Consden R, Doble A, Glynn L E, Nind A P. Production of chronic arthritis with ovalbumin. Ann Rheum Dis 1971; 30: 307-15.

${ }^{3}$ Steinberg M E, McCrae C R, Cohen L D, Schumacher H R. Pathogenesis of antigen-induced arthritis. Clin Orthop 1973; 97 : 248-60.

4 Henderson B, Glynn L E. Metabolic alterations in the synoviocytes in chronically inflamed knee joints in immune arthritis in the rabbit: comparison with rheumatoid arthritis. Br J Exp Pathol 1981; 62: 27-33.

${ }^{5}$ Henderson B, Glynn L E, Bitensky L, Chayen J. Evidence for cell division in synoviocytes in acutely inflamed rabbit joints. Ann Rheum Dis 1981; 40: 177-81.

- Chayen J, Bitensky L, Butcher R G. Practical Histochemistry. New York and London: Wiley, 1973.

7 Coulton L A. Temporal relationship between glucose 6-phosphate dehydrogenase activity and DNA-synthesis. Histochemistry 1977; 50: 207-15. 